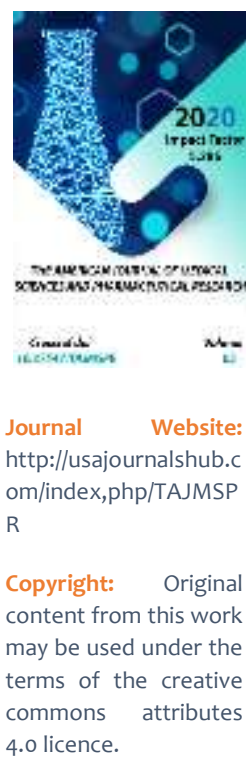

\title{
Dependence Of Protein-Energy Insufficiency On The Degree Of Motor Disorders In Infantile Cerebral Palsy
}

\author{
Mavlyanova Zilola Farhadovna \\ Candidate Of Medical Sciences, Associate Professor, Head Of The Department Of Medical \\ Rehabilitation, Sports Medicine And Traditional Medicine, Uzbekistan \\ Velilyaeva Aliye Sabrievna \\ Candidate Of Medical Sciences, Associate Professor, Head of The Department Of Psychiatry, \\ Medical Psychology And Narcology, Samarkand State Medical Institute, Uzbekistan
}

\section{ABSTRACT}

Purpose of research. To assess the impact of the severity of motor disorders in children with cerebral palsy on nutritional status.

Materials and methods of research. The study included 102 children with cerebral palsy aged 2 to 17 years, 60 boys $(58.8 \%$ ) and 42 girls ( $41.2 \%)$. The average age of the children was $7.23 \pm 4.9$ years. Patients were ranked by age group in accordance with the age classification of the GMFCS scale. All children underwent a comprehensive clinical and neurological examination, nutritional status assessment, and anthropometry (measurement of shoulder circumference and plicometry). During anthropometry, the control group included 30 healthy children with an average age of $7.7 \pm 4.2$ years.

Results. It was found that with an increase in the severity of motor disorders, the number of children with protein-energy deficiency increases from $50 \%$ at level I to $100 \%$ at level V on the GMFCS scale (the significance of differences in Pearson's Chi-square was confirmed statistically: 9.32, $p=0.002069$ ). At the same time, a severe degree of protein-energy insufficiency was observed mainly in double hemiplegia (amounting to 40.9\%). Prognostically, cerebral palsy was the most favorable type of spastic hemiparesis and spastic diplegia, with a predominance of protein-energy insufficiency of a mild degree, amounting to $45.8 \%$ and $60 \%$, respectively. In $71.6 \%$ of cases ( $n=73)$, children with cerebral palsy were diagnosed with oral-motor dysfunction of varying severity, problems with food consumption and, as a result, a noticeable lag in anabolic processes. Statistically significant differences were found in the frequency of feeding difficulties in children with levels I and V of motor abilities (Pearson's Chisquare: 20.12, $\quad p=0.000005)$.

\section{KEYWORDS}

Cerebral palsy, GMFCS scale, protein-energy deficiency. 


\section{INTRODUCTION}

The term "infantile cerebral palsy" refers to persistent disorders in the development of motor skills and maintaining posture that occur as a result of perinatal damage or abnormalities of the developing brain [6]. Cerebral palsy is one of the leading causes of childhood disability in the pathology of the nervous system. The representation of this group of diseases increases significantly in premature and deeply premature babies. And the frequency of complications in cerebral palsy in children is directly proportional to the level of motor deficit [1].

It is a well - known fact that Central nervous system damage in cerebral palsy occurs at the earliest stage of a child's development and affects not only motor abilities, coordination, and posture control, but also other non - motor areas of his life [10].

Despite the non-progressive nature of neurological deficits, patients with cerebral palsy experience a deterioration in motor functions with age. In childhood and adolescence, the loss of previously mastered motor skills is characteristic, primarily for children with levels III-V on the scale of global motor functions (Gross Motor Function Classification System, GMFCS) [6, 8], while with age, a gradual decrease in motor abilities occurs regardless of the level of GMFCS [7]. With adequate medical care, the life expectancy of most patients with cerebral palsy with mild to moderate motor disorders (GMFCS I - III) approaches the General population [4]. This is why the global motor function scale (GMFCS) is used to assess the motor function of a child with cerebral palsy in everyday life; its use is mandatory for dynamic monitoring of the child during rehabilitation [3].
Frequent manifestations of cerebral palsy that worsen its course and reduce the effectiveness of rehabilitation measures are also violations of the nutritional status.

Difficulties with swallowing and eating in children with cerebral palsy are described by Sherman V. et al. (2018) [11]. It is well known that problems related to the intake and assimilation of food and the metabolism of nutrients can be accompanied by a violation of the nutritional status (malnutrition, obesity) [2,5]. V. M. Studenikin and A. A. Buksh (2016), Aydin K. et al. also report on nutritional disorders in children with cerebral palsy. (2018), Scarpato E. et al. (2017) and García íniguez J. A. et al. (2018) [2,9].

Currently used classification of forms of cerebral palsy does not reflect the overall severity of the disease, expressed in the degree of motor function disorders, which is very important in clinical practice. In this connection, the article considers the possibility of using the global motor function scale (GMFCS) to assess the severity of motor disorders and their impact on nutritional status in children with cerebral palsy.

The aim of the study was to assess the impact of the severity of motor disorders in children with cerebral palsy on nutritional status.

\section{MATERIALS AND METHODS}

To achieve this goal, we analyzed the results of a survey of 102 children with cerebral palsy aged 2 to 17 years, boys-6o (58.8\%), girls -42 (41.2\%). The average age of the children was $7.23 \pm 4.9$ years. The study was conducted on the basis of the children's neurological Department of the Clinic of the Samarkand state medical Institute No. 1 and the children's neurological Department of the Samarkand 
regional children's multidisciplinary medical center.

All patients were ranked by age groups according to the GMFCS age classification: 2-4 years - 22 children (21.6\%), 4-6 years -32 children (31.4\%), 6-12 years - 25 children (24.5\%), over 12 years - 23 children (22.5\%). All children had a clinical and neurological examination, including a survey of children, their parents or guardians for complaints; analysis of medical records of outpatient and inpatient patients; assessment of nutritional status; examination by specialized specialists (consultation of an ophthalmologist, pediatrician, orthopedist, speech therapist, medical psychologist).

To assess the difficulties that children with cerebral palsy may experience while eating, a survey of parents of patients was conducted. They were asked to assess the child's motor abilities and self-care skills: the ability to eat independently or need help, the presence of regurgitation and vomiting during meals, and signs of dysphagia.

All patients underwent shoulder circumference measurement and plicometry - determination of the thickness of the skin-fat fold, which is one of the simplest methods for determining fat. In order to obtain the most accurate result, plicometry was performed using the DurninWomersly method at four standard points: above the triceps closer to its inner edge on the back of the shoulder with the arm lowered - the 1st point (when measuring, attention was paid to the fact that the measurement site was equally removed from the elbow and shoulder joints), the fold is taken vertically; over the biceps muscle at the level of the middle third of the shoulder - 2-nd point (points 1 and 2 in children with hemiparetic form of cerebral palsy the measurement was taken on healthy and not paralyzed side, the fold is taken vertically); 3-I dot at the lower angle of the scapula - it has produced pockets of skin under the angle of $45^{\circ}$ to the vertical in an oblique direction (from top to bottom, from inside to outside) just below any of the blades so that the skin fold was consistent with the direction of the line connecting the cervical vertebrae and hips, in some cases, resorted to the help of the assistant; The 4th point is $2 \mathrm{~cm}$ above the middle of the pupart fold in the groin area. When measuring the skin-fat fold with a caliper, the measurement was often performed on the right side of the body (with the exception of the hemiparetic form of cerebral palsy) on dry and clean skin; also, the measurement was not performed in places where the skin was damaged. When performing anthropometry, the control group consisted of 30 healthy children aged 2 to 17 years who were under dispensary observation in family polyclinics in Samarkand, with an average age of $7.7 \pm 4.2$ years.

To assess the severity of motor disorders in patients with cerebral palsy, the global motor function scale (GMFCS), developed in 1997 by employees of the Canadian University (McMaster University), was used. This classification is used to assess the level of motor disorders in children with cerebral palsy $[6,8]$, taking into account their functional capabilities, the need for auxiliary devices and mobility.

Statistical processing of the obtained data was performed using the Statistica 10 package and standard descriptive techniques, correlation analysis, and Pearson Chi-square.

\section{RESULTS}

Based on the results of a neurological examination, a form of cerebral palsy was established: spastic diplegia (DM) - 24.5\%, hemiparetic form (GPF) - 23.5\%, double 
hemiplegia (DG) $-21.7 \%$, hyperkinetic form (GF) $-18.6 \%$, atonic-astatic form (AAF) $-11.7 \%$.

The study group of children with cerebral palsy was divided into 5 subgroups depending on the motor deficit on the GMFCS scale: level I - 18 children (17.6\%), level II - 22 children (21.6\%), level III - 16 children (15.7\%), level IY - 20 children (19.6\%), level $Y$ - 26 children (25.5\%). Table 1 shows the gender and age characteristics of the examined patients depending on the level of motor ability on the GMFCS scale.

Table 1. Distribution of sick children by sex and age.

\begin{tabular}{|c|c|c|c|c|c|}
\hline \multirow{2}{*}{ GMFCS level } & \multirow{2}{*}{ Sex } & \multicolumn{5}{|c|}{ Age group } \\
\cline { 3 - 6 } & & $\begin{array}{c}\text { from 2 until 4 } \\
\text { age }\end{array}$ & $\begin{array}{c}\text { from 4 until } \\
6 \text { age }\end{array}$ & $\begin{array}{c}\text { from 6 until } \\
12 \text { age }\end{array}$ & $\begin{array}{c}\text { Over 12 } \\
\text { years old }\end{array}$ \\
\hline \multirow{2}{*}{ GMFCS I } & boys & 1 & 3 & 3 & 3 \\
\cline { 2 - 6 } & girls & 1 & 3 & 2 & 2 \\
\hline \multirow{2}{*}{ GMFCS II } & boys & 3 & 4 & 3 & 3 \\
\cline { 2 - 6 } & girls & 2 & 3 & 2 & 2 \\
\hline \multirow{2}{*}{ GMFCS III } & boys & 2 & 4 & 2 & 2 \\
\cline { 2 - 6 } & girls & 1 & 3 & 1 & 1 \\
\hline \multirow{2}{*}{ GMFCS IY } & boys & 3 & 3 & 3 & 3 \\
\cline { 2 - 6 } & girls & 2 & 2 & 2 & 2 \\
\hline GMFCS Y & boys & 4 & 4 & 4 & 3 \\
\cline { 2 - 6 } & girls & 3 & 3 & 3 & 2 \\
\hline
\end{tabular}

The IY level of GMFCS was crucial for the child's mobility $-35 \%$ of patients at THIS level could not move even within their room, $20 \%$ could leave the house with their hands (which corresponds to the 1st level of FMS). Almost all children with y-level GMFCS were immobilized, and only 7.7\% were able to move independently by crawling.

During clinical and neurological examination of children with cerebral palsy, adductor muscle syndrome and hamstring syndrome are most often diagnosed among spastic syndromes.
Adductor syndrome, characterized by spastic contraction of the long adductor muscles, short adductor muscle, and large adductor muscle with adduction of the patient's hip until they touch and intersect, is most commonly diagnosed in children with GMFCS iy and $Y$ levels, accounting for $90 \%$ and $92.3 \%$, respectively. Adductor syndrome resulted in significant difficulty standing and walking without additional support. When palpation in patients $\mathrm{mm}$. Gracilis, semimembranosus, semitendinosus, related to the internal flexors 
of the knee joint, in a position with a bent hip and slow extension in the knee joint, hamstring syndrome was noted. Its prevalence was also directly related to the level of motor deficits, reaching up to $100 \%$ in children with GMFCS $Y$ level and 95\% in children with GMFCS IY level motor deficits. In both cases, the increase in GMFCS was statistically significant $(p \leq 0.001)$.

Depending on the form of cerebral palsy, patients had different levels of motor abilities (figure 1). The relationship between the severity of cerebral palsy and the severity of motor disorders according to the GMFCS classification was revealed. In more severe forms of cerebral palsy, such as double hemiplegia, level $\mathrm{V}$ according to the classification of motor abilities was $90 \%$, which corresponded to severe violations of motor functions, significant restrictions on independent movements and almost always the inability to self-serve, including self-eating. In the hemiparetic form, GMFCS levels I and II prevailed-39\% each. Clinically, this was manifested by minor movement restrictions that did not require additional means of transportation (wheelchairs, walkers) and adult assistance. The atonic-astatic form, according to the data obtained, was the most favorable form of cerebral palsy, in which the severity of motor disorders was less pronounced. In these children, motor function levels ranged from GMFCS level I-14\% to level IV$14 \%$, with a predominance of level II- $43 \%$. It was in this form that the GMFCS level $V$ was not registered in any case. The presence of a correlation between the variables of average strength $(-0.572$ at $p<0.05)$ and negative orientation was reliably confirmed.

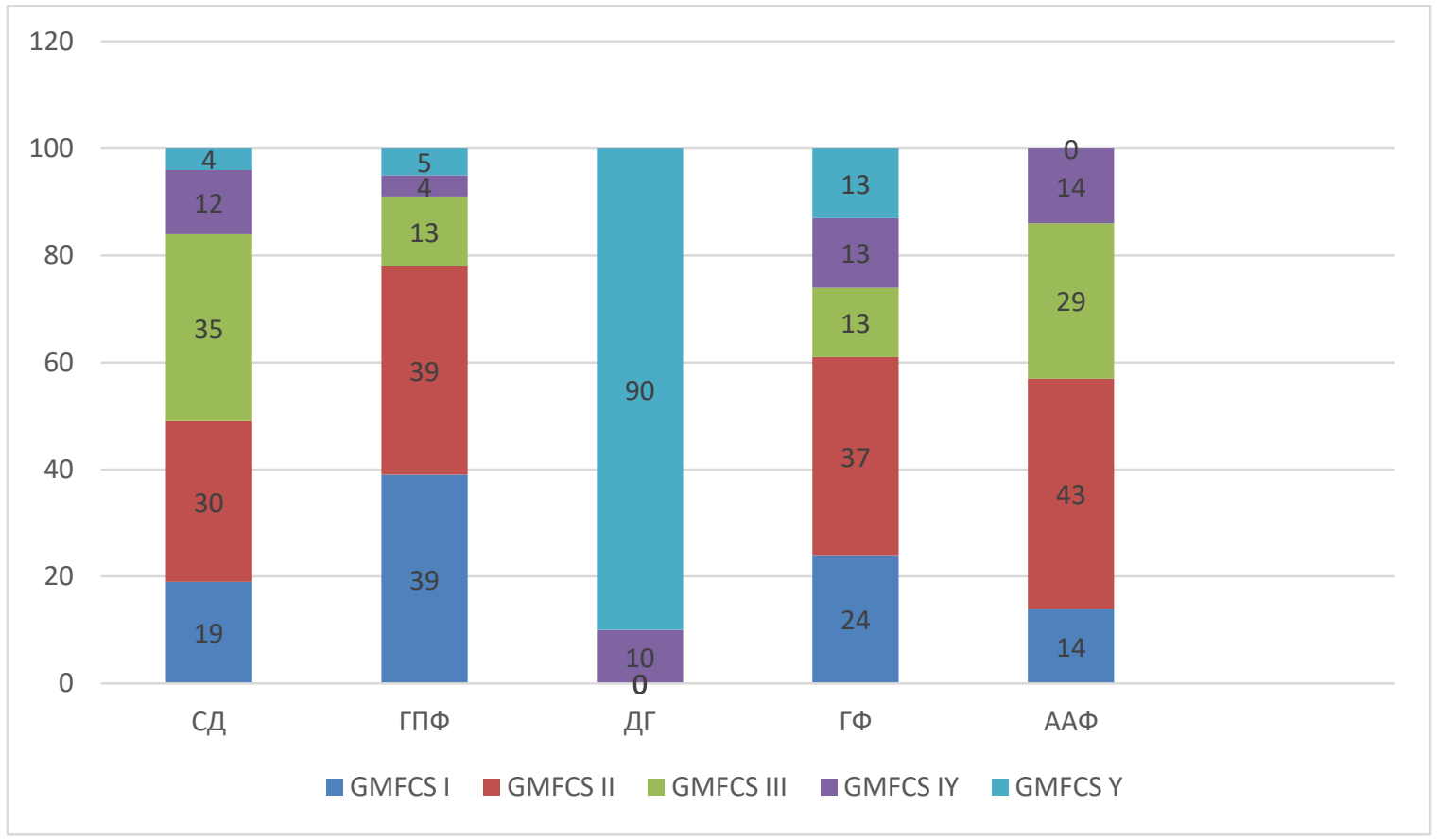

Figure 1. Frequency of occurrence of various forms of cerebral palsy at different levels of motor function impairment on the GMFCS scale. 
When comparing the levels of motor activity and the occurrence of protein-energy deficiency (table 2), it was noted that with an increase in the severity of motor disorders, the number of children with protein-energy deficiency increases. With a mild degree of motor disorders (corresponding to level I according to GMFCS), protein-energy deficiency is recorded in $50 \%$ of cases. In the group of children with severe motor disorders (level V GMFCS), protein-energy deficiency was detected in $100 \%$ of cases. Thus, the risk of developing malnutrition in children belonging to level $V$ on the GMFCS scale is twice as high as in level I (the significance of Pearson's Chisquare differences is statistically confirmed:
9.32, $\mathrm{p}=0.002069)$. In General, among patients with cerebral palsy, regardless of the form of the disease, a high percentage of children with swallowing disorders was observed, which potentially creates prerequisites for the development of protein-energy insufficiency. A severe degree of protein-energy deficiency was observed mainly in double hemiplegia (40.9\%). In the hyperkinetic form of cerebral palsy, protein-energy insufficiency of moderate severity prevailed $(36.8 \%$ of children). Prognostically, cerebral palsy was the most favorable type of spastic hemiparesis and spastic diplegia, with a predominance of protein-energy insufficiency of a mild degree, amounting to $45.8 \%$ and $60 \%$, respectively.

Table 2. Prevalence of protein-energy malnutrition at different levels on the GMFCS scale.

\begin{tabular}{|c|c|c|c|c|}
\hline \multirow{2}{*}{ GMFCS level } & \multicolumn{3}{|c|}{ The presence of protein-energy malnutrition } \\
\cline { 2 - 5 } & \multicolumn{2}{|c|}{ Diagnosed $(n=75)$} & \multicolumn{2}{c|}{ Not diagnosed $(\mathrm{n}=27)$} \\
\cline { 2 - 5 } & $\%$ & abs & $\%$ & abs \\
\hline I (n=18) & 50 & 9 & 50 & 9 \\
\hline II (n=22) & 54,5 & 12 & 45,5 & 10 \\
\hline III $(n=16)$ & 62,5 & 10 & 37,5 & 6 \\
\hline$I Y(n=20)$ & 90 & 18 & 10 & 2 \\
\hline$Y(n=26)$ & 100 & 26 & 0 & 0 \\
\hline
\end{tabular}

According to the results of the survey, children with more severe motor disorders were more likely to experience eating difficulties. The most pronounced oral-motor dysfunction and difficulties with food intake were observed in the group of patients with a y level on the
GMFCS scale (reaching 100\%), while its most frequent symptoms were problems with sucking (all examined patients had problems from the first days of life), later parents paid attention to problems with the introduction of complementary foods, including solid food, 
and chewing, as well as difficulties with drinking (up to 92.3\%). Less pronounced than in this subgroup of children, signs of oral motor dysfunction were noted at the IY level of GMFCS, amounting to $85 \%$. At the same time, $67(65.7 \%)$ of the examined children had a violation of the natural regulation of nutrition due to communication difficulties, since the patient could not clearly let them know about their hunger, satiety, and taste preferences. In General, in children with cerebral palsy, oralmotor dysfunction of varying severity and problems with food consumption occurred in $71.6 \%$ of cases $(n=73)$. Statistically significant differences were found in the frequency of feeding difficulties in children with $\mathrm{I}$ and $\mathrm{V}$ levels of motor abilities (Pearson's Chi-square: 20.12, $p=0.000005$ ) (table 3).

Table 3. Frequency of difficulty with food intake at various levels of motor impairment according to GMFCS (based on the results of the questionnaire).

\begin{tabular}{|c|c|c|c|c|}
\hline \multirow{2}{*}{ GMFCS } & \multicolumn{4}{|c|}{ Difficulty eating } \\
\cline { 2 - 5 } & \multicolumn{2}{|c|}{ Take place $(n=73)$} & \multicolumn{2}{c|}{ Do not take place $(n=29)$} \\
\cline { 2 - 5 } & $\%$ & abs & $\%$ & abs \\
\hline I (n=18) & 55,56 & 10 & 44,44 & 8 \\
\hline$I I(n=22)$ & 50 & 11 & 50 & 11 \\
\hline$I I I(n=16)$ & 56,25 & 9 & 43,75 & 7 \\
\hline$I Y(n=20)$ & 85 & 17 & 15 & 0 \\
\hline$Y(n=26)$ & 100 & 26 & 0 & 3 \\
\hline
\end{tabular}

To the questions "Whether the child has poor hand/mouth coordination leading to food loss" or" the Child does not eat independently", parents of children with cerebral palsy (the analysis was conducted among children over 5 years of age, $n=73)$ in $39(53.4 \%)$ cases emphasized that the child does not eat independently; 20 (27.4\%) had poor hand/mouth coordination leading to food loss; and in 14 (19.2\%) cases, the child did not have problems with food consumption. It is worth noting that at the heaviest level of GMFCS V, control over arbitrary movements was limited. Patients were unable to control the position of their head and torso and resist gravity; they needed adult help with self-care, movement, and feeding.

A comprehensive assessment of the nutritional status in patients with cerebral palsy, 
The American Journal of Medical Sciences and Pharmaceutical Research (ISSN - 2689-1026)

Published: November 28, 2020 | Pages: 32-41

Doi: https://doi.org/10.37547/TAJMSPR/Volumeo2Issue11-07

conducted by anthropometry, indicated a

noticeable lag in anabolic processes (table 4).

Table 4. Characteristics of muscle mass and subcutaneous fat in patients with cerebral palsy depending on the level of GMFCS.

\begin{tabular}{|c|c|c|c|c|c|c|}
\hline \multirow[b]{2}{*}{ Indicators } & \multicolumn{5}{|c|}{ Cerebral palsy $(n=102)$} & \multirow[b]{2}{*}{$\begin{array}{l}\text { Control } \\
\text { group }\end{array}$} \\
\hline & $\begin{array}{l}\text { GMFCS } \\
\text { I }(n=18)\end{array}$ & $\begin{array}{c}\text { GMFCS } \\
\text { II } \\
(n=22)\end{array}$ & $\begin{array}{l}\text { GMFCS III } \\
(n=16)\end{array}$ & $\begin{array}{l}\text { GMFCS IV } \\
(n=20)\end{array}$ & $\begin{array}{c}\text { GMFCS V } \\
(n=26)\end{array}$ & \\
\hline $\begin{array}{c}\text { Shoulder } \\
\text { circumference, } c \\
M\end{array}$ & $\begin{array}{c}14,11 \pm 0 \\
22^{*}\end{array}$ & $\begin{array}{c}14,03 \pm 0 \\
, 13^{*}\end{array}$ & $\begin{array}{c}13,03 \pm 0,31 * \\
* *\end{array}$ & $\begin{array}{c}12,89 \pm 0,25 * \\
* *\end{array}$ & $\begin{array}{c}11,78 \pm 0,66 * \\
* *\end{array}$ & $15,65 \pm 0,64$ \\
\hline $\begin{array}{c}\text { TTSFF at the 1st } \\
\text { point, } м м\end{array}$ & $\begin{array}{c}5,69 \pm 0 \\
81 * *\end{array}$ & $\begin{array}{c}5,35 \pm 0 \\
75 * *\end{array}$ & $\begin{array}{c}4,54 \pm 0,54 \\
* *\end{array}$ & $\begin{array}{c}4,53 \pm 0,33 \\
* *\end{array}$ & $\begin{array}{c}3,96 \pm 0,32 \\
* * *\end{array}$ & $7,4 \pm 0,65$ \\
\hline $\begin{array}{c}\text { TTSFF at the } 2 \text { nd } \\
\text { point, } м M\end{array}$ & $\begin{array}{c}7,53 \pm 0 \\
64 * *\end{array}$ & $\begin{array}{c}6,75 \pm 0 \\
11 * *\end{array}$ & $\begin{array}{c}5,86 \pm 0,35 \\
* *\end{array}$ & $\begin{array}{c}5,43 \pm 0,74 \\
* *\end{array}$ & $\begin{array}{c}5,21 \pm 0,43 \\
* * *\end{array}$ & $9,89 \pm 0,37$ \\
\hline $\begin{array}{c}\text { TTSFF at the } 3 \text { rd } \\
\text { point, } м м\end{array}$ & $\begin{array}{c}9,4 \pm 0,4 \\
3 \\
*\end{array}$ & $\begin{array}{c}8,87 \pm 0 \\
64 \\
*\end{array}$ & $\begin{array}{c}7,57 \pm 0,55 \\
*\end{array}$ & $\begin{array}{c}7,42 \pm 0,43 \\
* *\end{array}$ & $\begin{array}{c}6,54 \pm 0,23 \\
* * *\end{array}$ & $11,24 \pm 0,34$ \\
\hline $\begin{array}{c}\text { TTSFF at the } 4 \text { th } \\
\text { point, } м м\end{array}$ & $\begin{array}{c}3,08 \pm 0 \\
5 \\
*\end{array}$ & $\begin{array}{c}2,9 \pm 0,2 \\
5 \\
* *\end{array}$ & $\begin{array}{c}2,27 \pm 0,78 \\
* *\end{array}$ & $\begin{array}{c}2,1 \pm 0,74 \\
* *\end{array}$ & $\begin{array}{c}2,05 \pm 0,46 \\
* *\end{array}$ & $4,53 \pm 0,53$ \\
\hline Not & $\begin{array}{l}\text { of dat } \\
0,01 ; *\end{array}$ & $\begin{array}{l}\text { relatic } \\
P<0,0\end{array}$ & $\begin{array}{l}\text { o the indic } \\
\text { TTSFF }-t\end{array}$ & $\begin{array}{l}\text { rs of the cc } \\
\text { ness of the }\end{array}$ & $\begin{array}{l}\text { trol group } \\
\text { <in-fat fold }\end{array}$ & $<0,05 ; * *_{-}$ \\
\hline
\end{tabular}

In children with cerebral palsy, compared with healthy children, there was a slow increase not only in muscle mass detected when measuring the circumference of the upper extremities $(P<0.05-0.001)$, but also in subcutaneous fat when measuring the thickness of the skin-fat fold at the 3 rd point $(9,4 \pm 0,43 ; 8,87 \pm 0,64$; 7,57 $\pm 0,55 ; \quad 7,42 \pm 0,43 ; 6,54 \pm 0,23 \mathrm{~mm}$, respectively, subgroups against $11.24 \pm 0.34 \mathrm{~mm}$ in the control group; $\mathrm{P}<0.05-0.001)$ at the lower angle of the scapula and at the 4th point $2 \mathrm{~cm}$ above the middle of the pupart fold in the 
inguinal region $(3,08 \pm 0,5 ; 2,9 \pm 0,25 ; 2,27 \pm 0,78$; $2,1 \pm 0,74 ; 2.05 \pm 0.46 \mathrm{~mm}$, respectively, for subgroups with cerebral palsy versus $4.53 \pm 0.53$ $\mathrm{mm}$ in the control group; $\mathrm{P}<0.05-0.001$ ).

At the same time, nutritional status disorders in children with cerebral palsy were of varying severity depending on the level of motor disorders on the GMFCS scale: the most pronounced disorders were observed in patients with GMFCS levels IV and $V$ and were significant in relation to the I-th and II-th levels of GMFCS $(P<0.05-0.001)$. Thus, less pronounced symptoms of nutritional status disorders were determined at the level of GMFCS III, but they did not reach reliable values $(P>0.05)$.

\section{CONCLUSIONS}

1. there is a dependence of the levels of motor capabilities on the form of cerebral palsy and its severity. The GMFCS major motor function classification system is an easy-to-use technique and can be used to approximate motor abilities in children with cerebral palsy.

2. as a result of the study, it was found that the frequency of protein-energy malnutrition depends on the level of motor deficit on the GMFCS scale. The risk of developing protein-energy deficiency at the GMFCS V level is twice as high as at the GMFCS I level.

3. Difficulties with feeding children with cerebral palsy are directly related to their motor abilities, such as independent movement and self-care.

4. Given that severe forms of nutritional insufficiency develop in children with severe cerebral palsy on the GMFCS scale due to eating disorders, they need correction and nutritional rehabilitation.

5 .

\section{REFERENCES}

1. Abdel-Hamid, H.Z. Cerebral Palsy [electronic resource] / H.Z. AbdelHamid, A.S. Zeldin, A.T. Bazzano [et al] // Medscape. - 1994 - 2018. - Access mode:

https://emedicine.medscape.com/artic le/1179555-overview

2. Alicia Dixon-Ibarra, Gloria Krahn, Heidi Fredine, Anthony Cahill, Susan Jenkins Adults aging 'with' and 'into' paralysis: Epidemiological analyses of demography and health Disability and Health Journal October 2016, Volume 9, Issue 4, Pages 575-583

3. Compagnone, E. Functional classifications for cerebral palsy: correlations between the gross motor function classification system (GMFCS), the manual ability classification system (MACS) and the communication function classification system (CFCS) / E. Compagnone, J. Maniglio, S. Camposeo [et al] // Res. Dev. Disabil. - 2014. - V.35(11). - P.2651 -7 .

4. Hardeep Singh Malhotra, Ravindra Kumar Garg Dengue-associated hypokalemic paralysis: Causal or incidental? Journal of the Neurological Sciences 15 May 2014, Volume 340, Issues 1-2, Pages 19-25

5. Lavanya Bathini, Mohammed Jomah, Aleksandra Krajacic, Caroline Jeffery, Hamdy El-Hakim Acquired bilateral adductor laryngeal paralysis in neonates and children: A case series and a systematic review International Journal of Pediatric Otorhinolaryngology November 2014, Volume 78, Issue 11, Pages 1866-1869

6. Mamoru Niikura, Shin-Ichi Inoue, Shoichirou Mineo, Yutaroh Yamada, 
Fumie Kobayashi Experimental cerebral malaria is suppressed by disruption of nucleoside transporter 1 but not purine nucleoside phosphorylase Biochemical and Biophysical Research Communications15 March 2013, Volume 432, Issue 3, Pages 504-508

7. Mark D. Peterson, Paul Lin, Neil Kamdar, Elham Mahmoudi, Edward A. Hurvitz Cardiometabolic Morbidity in Adults With Cerebral Palsy and Spina Bifida The American Journal of Medicine In press, corrected proofAvailable online 17, July 2020

8. Munro, D. McKeen, J. Coolen Maternal respiratory distress and successful reversal with sugammadex during intrauterine transfusion with fetal paralysis International Journal of Obstetric Anesthesia August 2019, Volume 39, Pages 129-131

9. Rajendra Singh Jain, Pankaj Kumar Gupta, Rakesh Agrawal, Sunil Kumar, Kapil Khandelwal An unusual case of dengue infection presenting with hypokalemic paralysis with hypomagnesemia Journal of Clinical Virology August 2015, Volume 69, Pages 197-199

10. Teresa M. O Medical Management of Acute Facial Paralysis Otolaryngologic Clinics of North AmericaDecember 2018, Volume 51, Issue 6, Pages 10511075

11. Xiafei Liu, Chunling Bao, Guirong Dong Using acupoint-to-acupoint penetrative needling to treat poststroke spastic paralysis: a clinical progress review Journal of Traditional Chinese Medicine15 October 2014, Volume 34, Issue 5,Pages 609-615 